Veer, A.J.E. de, Janssens, J.M.A.M. Victim-orientated discipline, interpersonal understanding and guilt. Joûnal of Moral Education: 1994, 23(2), 165-182

\begin{tabular}{|l|l|}
\hline Postprint Version & 1.0 \\
\hline Journal website & $\underline{\text { http://www.informaworld.com/smpp/content } \sim \mathrm{db}=\text { all } \sim \text { content }=\mathrm{a} 746550683}$ \\
\hline Pubmed link & $10.1080 / 0305724940230205$ \\
\hline $\begin{array}{l}\text { DOI } \\
\text { This is a NIVEL certified Post Print, more info at http://www.nivel.eu }\end{array}$
\end{tabular}

\title{
VICTIM-ORIENTATED DISCIPLINE, INTERPERSONAL UNDERSTANDING AND GUILT
}

\author{
DE VEER, A.J.E., JANSSENS, J.M.A.M.
}

\begin{abstract}
According to Hoff man's theory of moral internalisation, parents' victim-orientated disciplinary strategies may stimulate a child to take another's needs into account. To test this hypothesis a cross-lagged panel design was used with two measurements within a time interval of two years. Data were gathered from 150 families. Victim-orientated discipline was related to a child's experience of guilt. Evidence for Hoffman's hypothesis about long-term effects of parents' disciplinary strategies was not found. Some evidence was found for the hypothesis that a child's level of interpersonal understanding mediates between parental disciplinary strategies and a child's internalisation of moral norms.
\end{abstract}

This paper addresses two issues concerning the relation between parental disciplinary strategies and a child's internalisation of the norm to take the needs of other persons into account. The first issue concerns the causal relation between parental discipline and a child's internalisation of this norm. The second issue concerns the mediating role of a child's level of interpersonal understanding between parental discipline and the internalisation of the norm to take the needs of other persons into account.

According to Hoffman $(1983,1984)$, guilt is a manifest expression of the internalisation of this norm. A child who is motivated to take the needs of other persons into account feels guilty after a transgression. A child who has not yet internalised this moral norm is assumed to have a moral orientation based on fear of external detection and punishment. Guilt arousal is a combination of empathic distress and the cognitive awareness of culpability for the other person's distress. Guilt is seen as a conscious, self-initiated and selfcritical reaction.

The social environment is extremely important in Hoffman's explanation of a child's internalisation of norms (Hoffman, 1970, 1975a, 1983, 1984). What kind of socialisation experiences may be of importance to the internalisation of the norm to take account of the other person's needs? According to Hoffman, disciplinary encounters within the family play a central role. In disciplinary encounters the parent attempts to change a child's behaviour. A child has done harm to another person, is going to harm someone, or omits helping another person who needs assistance. It appears as if the child either does not notice or neglects the needs of the other. Whenever parents try to change a child's behaviour, they have to inform the child about their wishes. Generally, two types of disciplinary strategies are distinguished: induction and power assertion. Induction refers to techniques in which the parent gives explanations or reasons for requiring the child to change his/her behaviour. Power assertion refers to behaviour as physical punishment, deprivation of material objects or privileges, the direct application of force, or the threat of any of these (Rollins \& Thomas, 1979).

A child who receives power assertive discipline probably has some idea (s)he has done something wrong. However, although power assertion may stimulate compliance, it is insufficient to promote internalisation. Because young children are hedonistically orientated and not aware of the needs of others, parents have to point out another's needs to the child. This is not the focus of power assertive disciplinary strategies. Inductive disciplinary reactions, however, can promote internalisation. According to Hoffman (1983), induction contributes to internalisation through two responses it evokes within a child. First, it evokes a 
Veer, A.J.E. de, Janssens, J.M.A.M. Victim-orientated discipline, interpersonal understanding and guilt. Journal of Moral Education: 1994, 23(2), 165-182

cognitive response; the inductive message directs a child's attention to the consequences of the child's behaviour for someone else. As a result the child can make a causal connection between his or her behaviour and the physical or psychological state of the victim. Secondly, an inductive message evokes an affective response. The message directs a child's attention to the other's needs and emotional state and, therefore, produces an empathic response.

Hoffman (1975b) emphasised the importance of a particular type of inductive reaction: "victim-orientated discipline". These techniques include pointing out the harmful consequences of a child's behaviour for the victim or asking a child to imagine him- or herself in the other person's place. Victim-orientated discipline also refers to techniques that suggest concrete acts of reparation and techniques that require a child to apologise. Following Hoffman, we hypothesised that messages that direct a child's attention toward the victim are particularly likely to stimulate a child to consider the needs of others. Victim-orientated discipline directs a child's attention to the consequences of his or her behaviour for someone else rather than for the self (e.g., "Look, now he is sad because you took his favourite toy"), teaches the child to refrain from moral transgressions (e.g., "How do you think X will feel if you break his toy?"), and teaches a child to help another (e.g., "Make up to the child for what you have done"). As a result a child can make a causal connection between his or her own action and the physical or psychological state of the victim.

In Hoffman's view a child's moral internalisation is primarily influenced by the way that parents carry out discipline. Several authors, however, argued that a child's moral internalisation influences the strategies used by parents. Bell $(1968,1977)$ suggested that parents do not have fixed techniques for socialising children. They have a repertoire of actions and different children trigger different actions. Bell's assumption was that children who show little moral internalisation are congenitally low in person orientation. They respond less to subtle hints, commands and parental expression of love than do children high in person orientation. Because of this unresponsiveness to social stimuli their parents will be less affectionate and will not appeal to a child's personal or social values. Similarly, Saltzstein (1976) suggested that a child's level of moral development determines the social influences to which a child is susceptible and the kind of discipline parents use. For example, children who conform to moral rules for extrinsic reasons are primarily susceptible to social influence aimed at compliance and, therefore, elicit various forms of power assertion from their parents, whereas children who conform to moral rules based on concern for the welfare of others elicit reasoning and other principled appeals from their parents. Saltzstein concluded that the process is best conceived as circular; the moral development of a child determines his/her susceptibility to different disciplinary techniques and these techniques, in turn, influence a child's moral development.

Although the study of a bidirectional model has found many advocates, empirical evidence for this model is scarce. The first aim of this study was to examine Hoffman's hypothesis that parental discipline precedes a child's internalisation of the norm to take the needs of other persons into account. How can Hoffman's hypothesis can be examined? A panel design has been recommended by several authors (Hoffman, 1979; Maccoby \& Martin, 1983; Saltzstein, 1976; Shaffer \& Brody, 1981). In a panel design (see Fig. 1) the behaviour of both participants (parent and child) is assessed at two measurement periods. Measures of parental discipline obtained at time 1 can be related to a child's internalisation of moral norms at time 2, providing a measure of the contribution of discipline to a child's internalisation of moral norms.

Conversely, measures of a child's internalisation of moral norms obtained at the beginning of the interval can be related to measures of parental discipline at the end of the interval in order to obtain a measure of the impact of a child on parental discipline.

The second aim of this study was to examine the mechanism that influences the internalisation of norms. Hoffman (1983) hypothesised that parental discipline influences a child's internalisation of the norm to take the needs of others into account by stimulating a child's perspective-taking in a moral encounter. The mediating role of perspective-taking in the relationship between disciplinary techniques and moral development has not often been the focus of research, though perspective-taking has been considered to be an important prerequisite of moral development (Kohlberg, 1976; Piaget, 1965; Selman, 1976). Hoffman (1983) also suggested that perspective-taking is important to the internalisation of the norm to take the needs of others into account. Infants are egocentric in the sense that they make no distinction between their view of social situations and possible alternative views. As a child becomes progressively better able to recognise the needs of others and to anticipate the consequences of his or her actions for others, a child may be more motivated to consider the other's needs and may feel guilty when transgressing a norm.

Hoffman (1983) not only hypothesised a relation between perspective-taking and a child's internalisation of moral norms, but also between parental discipline and perspective-taking. As stated previously, victim- 
Veer, A.J.E. de, Janssens, J.M.A.M. Victim-orientated discipline, interpersonal understanding and guilt. Joûnal of Moral Education: 1994, 23(2), 165-182

orientated discipline would enhance a child's perspective-taking ability. Because victim-orientated discipline promotes a child's perspective-taking ability and because perspective-taking has a positive influence on the internalisation of moral norms, Hoffman proposed a model in which perspective-taking has a mediating role between parental discipline and a child's internalisation of moral norms. Consequently, the second aim in this study was to test this hypothetical model in which perspective-taking mediates the relation between parental discipline and a child's internalisation of the norm to take the needs of others into account.

In the literature (Dekovic, 1992), a conceptual distinction is made between perspective-taking operationalised as social cognitive operations (which focus on the cognition about psychological processes within individual persons) and perspective-taking as interpersonal understanding (Selman et al., 1979), which focuses on relationships between people. For the purposes of this study we used the second definition of perspective-taking; to avoid conceptual confusion we used the concept of interpersonal understanding to indicate a child's ability to understand relationships between people.

\section{METHOD DESIGN}

Parental discipline, the child's interpersonal understanding and the internalisation of the norm to take the needs of others into account were assessed twice, with an interval of two years between both measurements. The interval was chosen somewhat arbitrary, given the fact that no norms exist in the literature concerning the optimal time lag (Gollob \& Reichardt, 1987. Because the studied effects might be dependent on the child's age, we used three age groups.

\section{SUBJECTS}

The sample consisted of 150 families with a child attending the second, fourth or sixth grade in one of 14 elementary schools in the Netherlands at the time of the first measurement. The total sample included 150 mothers, 152 fathers, 72 boys and 78 girls. During the first visit, 47 children attended second grade (.23 boys, 24 girls, mean $(M)=5 ; 9$ years), 50 children attended fourth grade ( 24 boys, 26 girls, $M=7 ; 11$ years) and 53 children attended sixth grade (25 boys, 28 girls, $M=9 ; 10$ years). Three per cent of the fathers were classified as unskilled labourers, 21\% skilled labourers, 20\% low-level employees, $9 \%$ self-employed people, $19 \%$ mid-level employees, and $21 \%$ higher occupations. There was an under-representation of the two lower levels and an over-representation of the two top levels.

\section{Procedure}

Each child was individually interviewed at school. The internalisation of moral norms was assessed with the Socio-Moral Interview (SMI). The child was also interviewed to assess his or her level of interpersonal understanding. The interviews were audiotaped and transcribed.

Parental discipline was assessed using the Discipline Technique Interview (DTI). Each parent was interviewed at home independently of the other parent. All interviews were audiotaped and transcribed.

This procedure was followed on both the first and the second measurement occasion.

\section{MEASURES}

Parental victim-orientated discipline. Each parent was asked to react to eight hypothetical situations. In each situation the son or daughter victimised another child. Because situational characteristics, such as the intention of a child and the consequences of the transgression, influence the parental disciplinary reaction (Grusec \& Kuczynski, 1980), the situations varied in these aspects. One of the stories was: "Your son and his friend are playing. Suddenly, your son tears the new shirt of his friend. The friend looks dismayed."

Other stories were about a child who hurt someone, broke someone's toy, made fun of a classmate, hit someone, cheated in a game, snatched someone's toy and a child who tore up someone's favourite poster. Following each situation the parents were asked how they would react in that situation. The situations were presented in random order.

The reactions of a parent to each hypothetical situation were coded with a modified version of the coding system used by Grusec and Kuczynski (1980). The coding system listed 25 disciplinary practices (interrater reliability was $81.5 \%$ ) such as physical punishment, deprivation of material objects or privileges, ignoring the child, disapproval of the child's behaviour, suggesting alternative ways of behaving, referring 
Veer, A.J.E. de, Janssens, J.M.A.M. Victim-orientated discipline, interpersonal understanding and guilt. Jounnal of Moral Education: 1994, 23(2), 165-182

to the consequences of the child's action for the victim, and stimulating to repair the damage. The category "victim-orientated discipline" consisted of behaviour categories stressing the position of the victim, i.e. referring to the material and/or personal consequences of the child's action for the victim and stimulating to repair the damage and/or to apologise. When a parent used many types of disciplinary strategies in response to the same misbehaviour, the victim-orientated message may be diffused. Other disciplinary reactions may distract a child's attention from the victim. Consequently, a parent's score on victim-orientated discipline was the proportion of victim-orientated reactions present in the total number of parental reactions.

To validate indirectly the data gathered in the DTI the interviewers were asked to rate the amount of inductive discipline the parents used after the second measurement. These ratings were based on all information available during the visit. The correlations between the rating and the amount of inductive discipline assessed during the interview were moderately high (for mothers $\mathrm{r}(149)=0.29, \mathrm{P}<0.05$; for fathers $r(125)=0.58, \mathrm{P}<0.01)$.

Interpersonal understanding. Selman (1976) distinguished several domains (e.g. peer relations and parentchild relations) in which the level of interpersonal understanding is manifested. The development of interpersonal understanding across domains is structurally parallel; that is, a high consistency of scores of interpersonal understanding is derived from different domains (Selman, 1980). In this research we confined ourselves to the domain of parent-child relations. Children were interviewed about four characteristic issues of the parent-child relationship: function and rationale for punishment (e.g., "Why do parents sometimes punish their children?", "Do you think that children should be punished when they disobey?", "How does punishment work?", "What does it do for children?"); demands for obedience (e.g. "Should children always obey their parents?", "Why do parents want their children to obey them?"); factors that cause conflicts (e.g., "What are some of the reasons that parents and children do not get along?"); and methods parents and children have for conflict resolution (e.g., "How can you best end a disagreement?").

A child's level of interpersonal understanding on every issue was scored according to the system developed by Selman et al. (1979). At the lowest level (stage 0) a child has egocentric and pragmatic conceptions of the parent-child relationship. Stage 1 conceptions are characterised by an identification with parental views. The main characteristic of stage 2 conceptions is their focus on the quality of the emotional ties between parent and child. And at the highest level coded in this investigation (stage 3), the parent-child relationship is considered to be both a reflection of and influence on a parent's and a child's personality functioning. Inter-rater reliabilities were $79 \%$ for function and rationale for punishment, $78 \%$ for demands for obedience and $79 \%$ and $83 \%$ for causes and resolutions of conflicts, respectively. The four scores were averaged (Selman et al., 1979). Averaging was based on the high internal consistency (Cronbach's alpha) of the four issue scores (0.68 at time 1 and 0.73 at time 2).

Evidence for the validity of these scores of interpersonal understanding was found in a study by Dekovic (1992). Dekovic found high partial correlations between interpersonal understanding and a child's measure of perspective-taking of another person's feelings and thoughts $(\mathrm{r}(125)=0.32, \mathrm{P}<0.01$; age partialed out), between interpersonal understanding and prosocial moral reasoning $(\mathrm{r}(125)=0.43, \mathrm{P}<0.01$; age partialed out) and between interpersonal understanding and a child's level of empathy $(\mathrm{r}(125)=0.34, \mathrm{P}<0.01$; age partialed out).

Guilt. To assess guilt the children were administered the Socio-Moral Interview (SMI, De Veer et al., 1987). The SMI consisted of four hypothetical stories describing a child who transgressed a norm (taking away a child's toy, hurting someone, deceiving someone, breaking another's toy). The protagonist in the stories was of the same sex and same age as the child. The interviewer read each story to a child and demonstrated it with pictures. An example of the stories was as follows.

A child is playing with his new ball. The ball rolls into the road and a car runs over the ball. The ball is broken. The child sadly walks away. The child then sees his friend playing with a ball and begins to cry. He then deliberately snatches the ball. Now his friend does not have a ball and begins to cry.

After checking whether a child understood the story, a set of standardised questions was asked. A short version of the SMI consisting of two stories was conducted with the youngest age group because of the limited attentional capacity. Children were encouraged to identify with the transgressor of the story. Subsequently, they were asked how the transgressor felt. The children were also asked to provide an ending to the story. Three (projective) guilt measures, analogous to the guilt measures of Thompson and Hoffman (1980), were used: guilt intensity, concern for victim and use of justice principles.

Guilt intensity. A child was asked to rate the intensity of guilt on a 7-point quantitative scale; $0=$ no guilt at all to $6=$ very guilty. 
Veer, A.J.E. de, Janssens, J.M.A.M. Victim-orientated discipline, interpersonal understanding and guilt. Joujnal of Moral Education: 1994, 23(2), 165-182

Concern for victim. This guilt measures was based on a child's explicit expressions of concern for the victim (in contrast to self-concern, such as worry over detection). The answers were coded on a 7-point scale. No guilt feelings or feelings based on self-concern were scored as 0 . A child also scored in one of the lower categories when they demonstrated distress about the possibility of punishment (score 1) or feared the child's revenge (score 2). In these cases, there was little or no concern for how the other person actually felt. At the high end of the scale, a child clearly showed concern for the victim (score 5) and sometimes a child spontaneously assumed the role of the victim (score 6). Some children reported feelings of guilt primarily because of behaving badly (e.g. violation of certain standards of conduct). They were not primarily motivated by self-interested concerns but also showed little or no concern for the victim. Only when a child tried to resolve the conflict with the victim was the answer scored as 4 , otherwise the answer was scored as 3 (inter-rater reliability was $88 \%$ ).

Use of justice principles. A third guilt measure was based on the quality of justice principles offered to explain guilt feelings. The children were asked whether they would feel differently if the act remained undetected by others. The measure was coded on a 6-point scale. The higher the score on this scale, the more a child utilised justice principles to explain guilt feelings. At the low end of the scale, a child simply did not feel guilty (score 0 ) or was largely concerned with external consequences: fear of detection and punishment (score 1) or fear of the revenge of the victim (score 2). When the act remained undetected, a child also frequently felt relief. At the high end of the scale (score 4 and 5), a child felt genuinely sorry for the victim independent of possible detection. The principled orientation of the child appeared stable. The difference between 4 and 5 , however, was that for a score of 5 a child not only indicated guilt as an outcome of the principled moral orientation, but also showed remorse which often led a child to apologise and attempt reparation, even when the wrongdoing went undetected. An intermediate level of the use of justice principles (score 3) was assigned when a child reported feelings of guilt and was not afraid of punishment, but wavered (i.e. showed some relief) in undetected transgression (inter-rarer reliability was $88 \%)$.

Correlations between the guilt measures were high. In order to reduce the number of variables for subsequent analyses we performed factor analyses on these three guilt measures. The factor analyses resulted in one-dimensional solutions. The factor loadings for all three indicators were high (respectively 0.88, 0.91 and 0.81 at time 1 and $0.90,0.93$ and 0.82 at time 2), and the explained variance sufficient. Furthermore, the factor loadings and explained variance of the data gathered at time 2 were almost equal. In subsequent analyses, therefore, the factor score on the factor "guilt" was used as an indicator of guilt.

One way of testing the validity of these guilt scores is to examine whether the guilt measure correlates to constructs which are theoretically related to guilt. Guilt is expected to relate to prosocial development. When anticipating the possible consequences for the victim, a child may experience guilt because of not helping. In our study we used two indicators of prosocial development; prosocial behaviour assessed with a Dutch version of the Prosocial Behavior Questionnaire of Weir and Duveen (1981), and the level of prosocial moral reasoning based on stories of Eisenberg-Berg and Hand (1979). At time 2 we found positive correlations (age partialed out) between guilt and prosocial behaviour $(\mathrm{r}(150)=0.30, \mathrm{P}<0.05)$ and between guilt and prosocial moral reasoning $(\mathrm{r}(150)=0.17, \mathrm{P}<0.05)$.

\section{RESULTS LINEAR RELATIONS BETWEEN VICTIM-ORIENTATED DISCIPLINE AND THE CHILD'S MORAL INTERNALISATION}

Linear relations between the use of victim-orientated discipline and moral internalisation are presented in Table I. Significant relations between victim-orientated discipline and guilt were found for both mothers $(r(149)=0.43, P<0.05)$ and fathers $(r(131)=0.30, P<0.05)$ at time 1 . When a parent frequently used victim-orientated discipline techniques a child appeared to obtain higher guilt scores. Moreover, the data of time 2 confirmed these findings. We may conclude that victim-orientated discipline and guilt are related. Children who experienced much guilt following transgression had parents who frequently used victimorientated discipline. Similarly, children who did not feel very guilty following a transgression most likely had parents who did not direct the child's attention towards the distress of others.

\section{CAUSES AND CONSEQUENCES OF PARENTAL DISCIPLINE AND MORAL INTERNALISATION}

So far, no causal conclusions could be drawn. In order to analyse whether victim-orientated discipline is an antecedent or a consequence of a child's moral internalisation LISREL analysis was used. We analysed 
Veer, A.J.E. de, Janssens, J.M.A.M. Victim-orientated discipline, interpersonal understanding and guilt. Joujnal of Moral Education: 1994, 23(2), 165-182

the data for the mother-child dyads and father-child dyads independently. Because guilt was found to be related to the child's age, all correlations among the measures for victim-orientated discipline and guilt were controlled for age. These partial correlations are reported in Table II (mothers) and Table III (fathers). Running ahead of the testing of the hypothesised mediating role of interpersonal understanding between parental discipline and guilt, this variable was also included in these tables.

Several criteria may be used for judging the fit of a LISREL model. First, the discrepancy between the hypothesized model and the observed data was tested using a chi-square test. Because the chi-square statistic is a direct function of sample size, however, almost any model is found not to fit with larger sample sizes (Anderson, 1987). Hence, additional indicators were used to judge the adequacy of a model. The second indicator was the goodness-of-fit index. This index estimates the degree to which a model accounts for the variances and covariances characteristic of the data. The third indicator was an adjusted goodnessof-fit index which adjusts the goodness-of-fit index to degrees of freedom and eliminates bias for models with few degrees of freedom. The fourth indicator was the root mean square residual, which is the average of the square of the residuals (mean of unexplained variances and covariances). A fifth criterion for judging the fit of a model was the statistical significance of each path coefficient (t-values) and the non-significance of the normalised residuals. Finally, a model was also evaluated by examining the amount of variance explained in the dependent variables.

In our first LISREL analyses we analysed whether parental discipline at time 2 was influenced by parental discipline at time 1 , and whether guilt at time 2 was dependent on guilt at time 1 (see Fig. 1). The crosslagged effect from guilt at time 1 on parental discipline at time 2 and the cross-lagged effect from discipline at time 1 on guilt at time 2 were also tested in the first LISREL analyses.

The hypothesised model (see Fig. 1) fitted neither for mother nor for fathers. The chi-square statistic showed that the model based on mother-data did not adequately fit the data $\left(\operatorname{chi}^{2}(1)=5.22, \mathrm{P}=0.022\right)$. The goodness-of-fit index was acceptable (0.982), but the adjusted goodness-of-fit index was rather low (0.824). The root mean square residual was acceptable (0.052). The cross-lagged path estimates (the path from maternal victim-orientated discipline at time 1 to guilt at time 2 and the path from guilt at time 1 to maternal victim-orientated discipline at time 2$)$ did not reach significance $(\mathrm{P}>0.05)$. Thus the way mothers disciplined did not influence the child's future guilt experiences. Also, no evidence was found for the hypothesis that mothers adapted their disciplining to the child's guilt experiences.

We found similar results with LISREL analyses based on father-data. First, a model with cross-lagged paths was tested (Fig. 1$)$. The significant chi-square statistic $\left(\operatorname{chi}^{2}(1)=7.58, \mathrm{P}=0.006\right)$ indicated that the data did not fit the model. The goodness-of-fit index was acceptable (0.971), but the adjusted goodness-offit index was low (0.714). The root mean square residual was acceptable (0.063). Neither of the t-values of the cross-lagged paths were significant $(\mathrm{P}>0.05)$ and, as with the data of mothers, the significant path coefficients between the scores of victim-orientated discipline at both measurement occasions and between the two guilt scores indicated a stability of these measures.

These results suggested a reduced model in which the variables guilt and parental discipline were stable across time. In this model, victim-orientated discipline and the child's guilt at time 2 were explained by the relationship between these variables at time 1 and the stability of these variables. No cross-lagged paths were hypothesised in this model. Moreover, based on modification indices a relation between the unexplained variance of victim-orientated discipline at time 2 and the unexplained variance of guilt at time 2 was introduced.

These revisited models were tested again. LISREL analyses showed a good fit both for the model based on mother-data and the model based on father-data (see Figs. 2 and 3). The non-significant chi-square statistics and the fact that the values of the (adjusted) goodness-of-fit indices fell well within the acceptable ranges (see Figs. 2 and 3) suggested that the model was well-defined. The normalised residuals were nonsignificant; the stability coefficients were significant. Although the variables showed stability over time this does not imply that the parents and children have not changed over the two years. That is, only $16 \%$ of the variance in maternal victim-orientated discipline at time 2, 25\% of the variance in paternal victimorientated discipline at time 2 and $9 \%$ of the variance in the child's guilt at time 2 was explained by the scores from two previous years.

In summary, long term effects of parents on children and children on parents were not found in this research. On both measurement occasions victim-orientated discipline was found to be associated with the child's guilt experiences, and this was found to apply to mothers as well as fathers. This repeated finding suggested that the relation between victim-orientated discipline and guilt was valid. 
Veer, A.J.E. de, Janssens, J.M.A.M. Victim-orientated discipline, interpersonal understanding and guilt. Journal of Moral Education: 1994, 23(2), 165-182

\section{THE ROLE OF INTERPERSONAL UNDERSTANDING IN THE RELATION BETWEEN VICTIM-ORIENTATED DISCIPLINE AND GUILT}

One of the aims in this study was to examine the mediating role of interpersonal understanding in the relation between victim-orientated discipline and guilt. Long-term effects of victim-orientated discipline on a child's feelings of guilt were not found, which made it difficult to test the hypothesis that interpersonal understanding mediated between parental discipline and guilt. We decided to test the possibly mediating role of interpersonal understanding in this relation using cross-sectional data. As Gollob and Reichardt (1987) observed, models based on cross-sectional data fail to consider the influence of a variable on itself over time (stability). Furthermore, these models do not consider already existing associations between the variables in the model. Already existing relations between such variables can be seen as background variables. When these background variables are not part of the model, the values of the paths will be overestimated. Because data from two measurement occasions were available in the present study, we could start from the background relations present at time 1 and tested a model based on the data at time 2 (Fig. 4).

The correlations presented in Table II were the input data for the LISREL analysis of the mother-child dyads. In Fig. 4 the model based on the analysis of the mother-child dyads is presented. As can be seen, the model shown in Fig. 4 provided a good fit: $\mathrm{X}^{2}(7)=10.10(\mathrm{P}=0.183)$, goodness-of-fit index $=0.977$, adjusted goodness-of-fit $=0.931$, root mean square residual $=0.055$. The non-significant chi-square statistic, and the fact that the values of the latter three indicators fall well within the acceptable ranges, suggested that the model was well-defined. Only $10 \%$ of the variance in guilt at time 2 was explained by the other variables in the model. An inspection of the paths showed low but significant regression coefficients for maternal victim-orientated discipline on interpersonal understanding and from interpersonal understanding on guilt. This indicated that the hypothesised model in which victim-orientated discipline influences guilt by stimulating the child's interpersonal understanding was confirmed.

The same model was also tested on father-data. The correlation coefficients of father-child dyads are presented in Table III, and Fig. 5 is the structural representation of this model. This model also provided a viable account of the observed data, as indicated by the non-significant chi-square statistic $\left(X^{2}(7)=9.32\right.$, $\mathrm{P}=0.231$ ) and the fact that the values of the three goodness-of-fit indicators all fall in the appropriate range (see Fig. 5). The model explained $10 \%$ of the variance in the children's guilt scores at time 2 . Moreover, all of the regression coefficients were found to be significant. It should be noted that the path estimates for victim-orientated discipline on interpersonal understanding and for interpersonal understanding on guilt were almost equal to the regression coefficients found in the mother-child dyads.

It may be concluded that a model in which victim-orientated discipline stimulates interpersonal understanding, which in turn stimulates guilt, fits the observed data. That is, a parent who frequently uses victim-orientated disciplinary techniques stimulates interpersonal understanding, and the higher the child's level of interpersonal understanding the more guilt the child may experience following a transgression. It should be noted, however, that the regression coefficients found in the LISREL analyses were low.

\section{DISCUSSION}

The aim of the present research was to investigate the relationship between disciplinary techniques used by parents and a child's internalisation of the norm to take the needs of others into account. The first question was whether the long-term influence of parental discipline and children's internalisation of moral norms is unidirectional. The second question was whether a child's level of interpersonal understanding mediates between parental discipline and a child's internalisation of the norm to take the needs of others into account.

Victim-orientated discipline was found to be related to interpersonal understanding and to guilt. The strength of the relationships was not particularly strong, but the correlations were replicated across the two measurements and held for both mother-child dyads and father--child dyads. The findings verified Hoffman's suggestion that victim-orientated discipline is especially important for stimulating interpersonal understanding and the internalisation of norms (Hoffman, 1970). In cross-sectional analyses the mediating role of interpersonal understanding in the relation between discipline and guilt appeared to be confirmed. Note, however, that the verification of this model does not exclude the possibility that a child's moral internalisation also influences the way parents discipline their children. That is, the data might also fit a model in which internalisation of a moral norm mediates the influence of a child's level of interpersonal understanding of the parental use of victim-orientated discipline. 
Veer, A.J.E. de, Janssens, J.M.A.M. Victim-orientated discipline, interpersonal understanding and guilt. Journal of Moral Education: 1994, 23(2), 165-182

Three explanations can be offered for the importance of victim-orientated discipline to a child's internalisation of the norm to take the needs of others into account. First, victim-orientated discipline is distinguished from inductive discipline because inductive discipline includes, to a large extent, only oneway communication strategies (i.e. didactic induction, according to Peterson \& Skevington, 1988). Such explanations often do not challenge a child's existing point of view or stimulate them to rectify his or her actions. Moreover, inductive discipline does not necessarily direct a child's attention to the other's distress and does not necessarily explain the nature of it. Victim-orientated discipline, on the other hand, clearly directs a child's attention to the other's distress. Victim-orientated discipline was operationalised as stressing the consequences of a child's behaviour for others, stimulating a child to take the perspective of another, and stimulating repair. By pointing out the needs of the other person, a parent may create a conflict between hedonistic needs and the needs of others, and such a conflict may be of particular importance for stimulating a child's internalisation of the norm to take the needs of others into account (Hoffman, 1975a).

A second characteristic of victim-orientated discipline that is not always present in the inductive message is the demand aspect. Hoffman (1970) assumed that without some communication of responsibility a child might respond empathically but dissociate himself or herself from the causal act or deny it. Victimorientated discipline not only informs a child about the victim's distress but also appeals to a child's responsibility by stimulating interpersonal understanding and repair. "Demandingness" refers to behaviour by which a parent makes an appeal to a child's responsibility, to mature behaviour, to independence or to resolution of problems. A clear relation between "demandingness" and moral development has been documented (Maccoby, 1980). Victim-orientated discipline clearly communicates to a child that he or she is responsible for the distress of another person and that he or she must take the needs of the victim into account.

A third possible characteristic that differentiates between victim-orientated discipline and inductive discipline is the suggestion that a child repairs the damage or apologises. With the use of victim-orientated discipline, a parent not only points out the situation of the victim to a child, but also communicates how a child might relieve the victim's distress. From this viewpoint, victim-orientated discipline may teach children that they can control their environment. Such perceived control may influence behaviour beyond the parent-child interaction. For example, Skinner (1986) has suggested that a child's perceived control may take over or supplement a mother's role in guiding and regulating child behaviour in problem-solving tasks. It can be speculated, therefore, that perceived control also plays a role in a child's moral internalisation and moral behaviour.

Across a period of two years no cross-lagged causal linear relations could be found between victimorientated discipline and guilt. That is, maternal and paternal victim-orientated discipline on the first measurement occasion was not related to guilt on the second measurement occasion two years later. What mechanisms might account for the lack of a long-term relation between discipline and guilt? First, the agerange of the children in this study may not have been appropriate for examining the long-term relation between discipline and guilt. For example, the relation between discipline and guilt may already be established before a child's fifth year. Encounters with a moral norm occur in early interaction with parents, brothers, sisters and peers. The study of parent-child interactions during preschool years may be critical for the investigation of long-term relations between discipline and guilt. Secondly, the lag between measurements might not be suitable to capture long-term influences. During a period of two years many things can happen that also reduce the correlation between the initial measurements and measurements two years later. Thus long-term influences may be found when another time lag is chosen. The use of repeated measurements across a somewhat smaller interval is therefore recommended for future research, because both minor and major long-term changes can then be documented. A final possibility is that little or no long-term relation between parental disciplining and a child's internalisation of moral norms exists. A transactional model may characterize better the relation between these two variables. If we assume that both the age of the children and the time interval were correctly selected, then it appears that no evidence has been found for Hoffman's claim that parental discipline has a unidirectional influence on a child's internalisation of moral norms. These results raise questions about the utility of an unidirectional or bidirectional model and the cross-lagged design for understanding the relation between parental discipline and a child's internalisation of moral norms. The course of a parent-child interaction may be determined by both the parent's long-term preference for a victim-orientated style and a child's internalisation of moral norms. Within a single episode both parent and child influence each other. Because of these enduring influences of each parmer on the other, the question of who influences whom within an episode may not be 
Veer, A.J.E. de, Janssens, J.M.A.M. Victim-orientated discipline, interpersonal understanding and guilt. Jou of Moral Education: 1994, 23(2), 165-182

relevant any more and it may become impossible to disentangle the reciprocal influences. Individual episodes may confirm already present cognitions, expectations, preferences or behavioural tendencies, rather than elicit change. Only minor changes in future preferences of a particular discipline technique and a child's internalisation of moral norms will take place. Consequently, every new episode can be considered as a continuation and confirmation of the preceding episodes. At best, small changes in both preferences for victim-orientated discipline and a child's internalisation of moral norms may occur as the result of a sequence of reciprocal interactions.

\section{TABLES}

TABLE I. PEARSON CORRELATIONS BETWEEN PARENTAL USE OF VICTIM-ORIENTATED DISCIPLINE AND THE CHILD'S GUILT

Legend for Chart:
A - No heading
B - Time 1; Mother
C - Time 1; Father
D - Time 2; Mother
E - Time 2; Father

A

B

C

D

E

Time 1 guilt

Time 2 guilt

$0.43\left[{ }^{*}\right]$

$0.30\left[{ }^{*}\right]$

$0.26\left[{ }^{*}\right]$

0.13

$* \mathrm{P}<0.05$. 
Veer, A.J.E. de, Janssens, J.M.A.M. Victim-orientated discipline, interpersonal understanding and guilt. Jou of Moral Education: 1994, 23(2), 165-182

TABLE II. INTERCORRELATIONS BETWEEN MATERNAL VICTIM-ORIENTATED DISCIPLINE, INTERPERSONAL UNDERSTANDING AND GUILT (CONTROLLED FOR AGE)

Legend for Chart:

A - No heading

B - Time 1; Maternal victim-oriented discipline

C - Time 1; Interpersonal understanding

D - Time 1; Guilt

E - Time 2; Maternal victim-oriented discipline

F - Time 2; Interpersonal understanding

G - Time 2; Guilt

A

B $\quad$ C

Maternal victim-

orientated

E

$\mathrm{F}$

G

discipline
$\odot .39\left[{ }^{*}\right]$
$\odot .23\left[{ }^{*}\right]$
$0.46\left[{ }^{*}\right]$
$0.18\left[{ }^{*}\right]$
$\odot . \odot 8$

Interpersonal

understanding

$0.22\left[{ }^{*}\right]$

$\left.0.34{ }^{-*}\right]$

$0.37\left[{ }^{*}\right]$

Guilt

$0.25\left[{ }^{*}\right]$

$0.25\left[{ }^{*}\right]$

$0.16\left[{ }^{*}\right]$

Time 2

Maternal victim-orientated

discipline

$-$

$\left.-0.24{ }^{*}\right]$

$0.22\left[{ }^{*}\right]$

Interpersonal

understanding

- -

$0.30\left[{ }^{*}\right]$

Guilt

$* \mathrm{P}<0.05$. 
Veer, A.J.E. de, Janssens, J.M.A.M. Victim-orientated discipline, interpersonal understanding and guilt. Jou of Moral Education: 1994, 23(2), 165-182

TABLE III. INTERCORRELATIONS BETWEEN PATERNAL VICTIM-ORIENTATED DISCIPLINE, INTERPERSONAL UNDERSTANDING AND GUILT (CONTROLLED FOR AGE)

Legend for Chart:

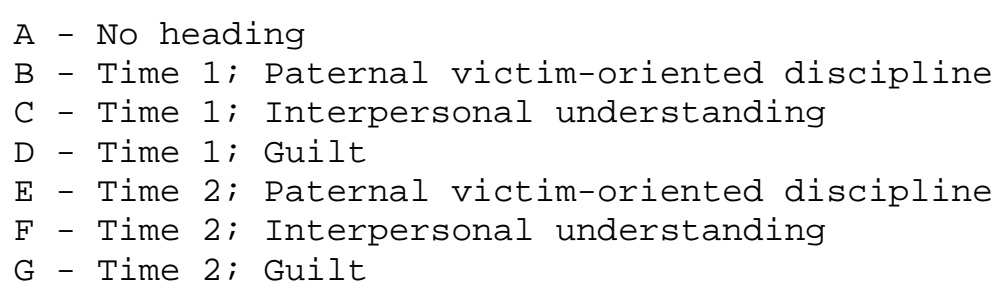

A

$\begin{array}{lll}B & C & D \\ E & \text { F } & \text { G }\end{array}$

Paternal victim-

orientated discipline

$0.51\left[^{*}\right]$

$0.22\left[{ }^{*}\right]$

$\odot .26\left[{ }^{*}\right]$

$\odot .13$

Interpersonal

understanding

$$
0.06
$$

$0.34\left[{ }^{*}\right]$

$\odot .37\left[{ }^{*}\right]$

Guilt

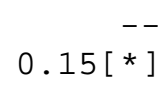

$\odot .25\left[{ }^{*}\right]$

$0.16\left[{ }^{*}\right]$

Time 2

Paternal victim-

orientated

discipline

Interpersonal

understanding

Guilt

$* \mathrm{P}<0.05$.

$\begin{array}{lrr}-- & -- & { }^{--} \\ -- & \left.0.23{ }^{*}\right] & 0.22\left[^{*}\right] \\ -- & -- & -- \\ -- & -- & 0.27\left[^{*}\right] \\ -- & -- & -- \\ -- & -- & -\end{array}$

DIAGRAM: FIG. 1. Panel design used in this study.

DIAGRAM: FIG. 2. Structural representation of the reduced model of relations between maternal victimorientated discipline and guilt $(n=144)$. Goodness-of-fit indicators: chi $^{2}(2)=1.61(P=0.448)$; goodness-offit $=0.994$; adjusted goodness-of-fit $=0.972$; root mean square residual $=0.027$. Proportion of variance in victim-orientated discipline time 2 explained=0.16; proportion of variance in guilt time 2 explained $=0.09$.

DIAGRAM: FIG. 3. Structural representation of the reduced model of relations between paternal victimorientated discipline and guilt $(n=126)$. Goodness-of-fit indicators: chi ${ }^{2}(2)=0.47(P=0.789)$; goodness-offit $=0.998$; adjusted goodness-of-fit $=0.991$; root mean square residual $=0.022$. Proportion of variance in victim-orientated discipline time 2 explained $=0.25$; proportion of variance in guilt time 2 explained $=0.09$.

DIAGRAM: FIG. 4. Structural representation of the model testing mediation of the relation between maternal victim-orientated discipline and guilt by interpersonal understanding $(n=144)$. Goodness-of-fit indicators: $X^{2}(7)=10.10(P=0.183)$; goodness-of-fit $=0.977$; adjusted goodness-of-fit $=0.931$; root mean square residual $=0.055$. Proportion of variance in guilt time 2 explained $=0.10$.

DIAGRAM: FIG. 5. Structural representation of the model testing mediation of the relation between paternal victim-orientated discipline and guilt by interpersonal understanding $(n=126)$. Goodness-of-fit indicators: $X^{2}(7)=9.32(P=0.231)$; goodness-of-fit = 0.076; adjusted goodness-of-fit = 0.929; root mean square residual $=0.051$. Proportion of variance in guilt time 2 explained $=0.10$. 
Veer, A.J.E. de, Janssens, J.M.A.M. Victim-orientated discipline, interpersonal understanding and guilt. Joutnal of Moral Education: 1994, 23(2), 165-182

\section{REFERENCES}

ANDERSON, J. (1987) Structural equation models in the social and behavioral sciences: model building, Child Development, 58, pp. 49-64.

BELL, R. (1968) A reinterpretation of the direction of effect in studies of socialization, Psychological Review, 75, pp. 81-95.

BELL, R. (1977) Socialization findings examined, in: R. BELL \& L. HARPER (Eds) Child Effects on Adults, pp. 53-84 (Hillsdale, NJ, Erlbaum).

DEKOVIC, M. (1992) The Role of Parents in the Development of Child's Peer Acceptance (Assen, The Netherlands, Van Gorcum).

DE VEER, A., JANSSENS, J. \& GERRIS, J. (1987) Het Socio-Moreel Interview (Nijmegen, The Netherlands, University of Nijmegen).

EISENBERG-BERG, N. \& HAND, M. (1979) The relationship of pre-schoolers' reasoning about prosocial moral conflicts to prosocial behavior, Child Development, 50, pp. 356-364.

GOLLOB, H. \& REICHARDT, C. (1987) Taking account of time lags in causal models, Child Development, 58, pp. 80-92.

GRUSEC, J.E. \& KUCZYNSKI, L. (1980) Direction of effect in socialization. A comparison of the parent's versus the child's behavior as determinants of disciplinary techniques, Developmental Psychology, 16, pp. 1-19.

HOFFMAN, M.L. (1970) Moral development, in: P. H. MUSSEN (Ed.) Carmichael's Handbook of Child Psychology, Vol. II, pp. 261-359 (New York, Wiley).

HOFFMAN, M.L. (1975a) Moral internalization, parental power, and the nature of parent-child interaction, Developmental Psychology, 11, pp. 228-239.

HOFFMAN, M.L. (1975b) Altruistic behavior and the parent-child relationship, Journal of Personality and Social Psychology, 31, pp. 937-943.

HOFFMAN, M.L. (1979) Development of moral thought, feeling, and behavior, American Psychologist, 34, pp. 958-966.

HOFFMAN, M.L. (1983) Affective and cognitive processes in moral internalization, in: E. T. HIGGINS, D. N. RUBLE \& W. W. HARTUP (Eds) Social Cognition and Social Development. A Sociocultural Perspective, pp. 236-274 (New York, Cambridge University Press).

HOFFMAN, M.L. (1984) Parent discipline, moral internalization and development of prosocial motivation, in: E. STAUB, D. BAR-TAL, J. KARYLOWSKI \& J. REYKOWSKI (Eds) Development and Maintenance of Prosocial Behavior, pp. 117-137 (New York, Plenum Press).

KOHLBERG, L. (1976) Moral stages and moralisation. The cognitive-developmental approach, in: T. LICKONA (Ed.) Moral Development and Behavior. Theory, Research and Social Issues, pp. 253-265 (New York, Holt, Rinehart \& Winston).

MACCOBY, E. (1980) Social Development: Psychological Growth and the Parent-Child Relationship (New York, Harcourt Brace Jonavovich).

MACCOBY, E.E. \& MARTIN, J.A. (1983) Socialization in the context of the family: parent-child interaction, in: P. H. MUSSEN (Ed.) Carmichael's Handbook of Child Psychology: Vol. IV. Socialization, Personality and Social Development, pp. 1-101 (New York, Wiley).

PETERSON, C. \& SKEVINGTON, S. (1988) The relation between young children's cognitive role-taking and mother's preference for a conflict-inducing childrearing method, Journal of Genetic Psychology, 149, pp. 163-174.

PIAGET, J. (1965) The Moral Judgement of the Child (London, Routledge \& Kegan Paul).

ROLLINS, B.C, \& THOMAS, D.L. (1979) Parental support, power and control techniques in the socialization of children, in: W. R. BURR, R. HILL, F. I. NYE \& I. L. REISS (Eds) Contemporary Theories about the Family: Vol. 1. Research Based Theories, pp. 317-364 (London, Free Press).

SALTZSTEN, H.D. (1976) Social influence and moral development. A perspective on the role of parents and peers, in: T. LICKONA (Ed.) Moral Development and Behavior. Theory, Research and Social Issues, pp. 253-265 (New York, Holt, Rinehart \& Winston).

SELMAN, R.L. (1976) Social-cognitive understanding. A guide to educational and clinical practice, in: T. LICKONA (Ed.) Moral Development and Behavior. Theory, Research and Social Issues, pp. 299-316 (New York, Holt, Rinehart \& Winston).

SELMAN, R.L. (1980) The Growth of Interpersonal Understanding; Developmental and Clinical Analysis (New York, Academic Press).

SELMAN, R.L., JAQUETTE, D. \& BRUSS-SAUNDERS, E. (1979) Assessing interpersonal understanding: an interview and scoring manual in five parts constructed by the Harvard-Judge Baker Social Reasoning Project (Boston, Judge Baker Guidance Center). 
Veer, A.J.E. de, Janssens, J.M.A.M. Victim-orientated discipline, interpersonal understanding and guilt. Jou of Moral Education: 1994, 23(2), 165-182

SHAFFER, D. \& BRODY, G. (1981) Parental and peer influences on moral development, in: R. W. HENDERSON (Ed.) Parent-Child Interaction. Theory, Research and Prospects, pp. 83-124 (New York, Academic Press).

SKINNER, E. (1986) The origins of young children's perceived control: mother contingent and sensitive behavior, International Journal of Behavioral Development, 9, pp. 359-382.

THOMPSON, R. \& HOFFMAN, M. (1980) Empathy and the development of guilt in children, Developmental Psychology, 16, pp. 155-156.

WEIR, K. \& DUVEEN, G. (1981) Further development and validation of the social behavior questionnaire for use by teachers, Journal of Child Psychology and Psychiatry, 22, pp. 357-374. 